\title{
Biopsia renal en pacientes con toxemia del embarazo
}

\author{
Doctor Alvaro Cuadros \\ Auxiliar de Cátedra. Facultad de Medicina. Universidad del Valle
}

Doctor Reinaldo Mora Restrepo.

Residente de la Clínica de Maternidad de Cali.

INFORME PRELIMINAR

Desde hace seis meses hemos incorporado a nuestro programa general de investigación en toxemia gravídica, un estudio específico en la morfología renal. El propósito de este estudio es obtener datos adicionales, que nos ayuden en última instancia a en. tender mejor esta importante complicación del embarazo y que nos permita una mayor precisión en cuanto al diagnóstico y al pronóstico se refiere. El tejido renal en estas pacientes lo hemos obtenido por medio de punción-biopsia, ya por la vía percutánea c directamente durante la operación cesárea. Queremos presen. tar este estudio únicamente con el ánimo de informar de los trabajos que estamos realizando en este tema, y no queremos ni podemos sacar ninguna conclusión respecto a la patología encon. trada en relación con pacientes que padecen de toxemia del em. barazo, por la razón obvia de tener un número muy reducido de casos estudiados en esta forma, además de no poder hacer un diagnóstico definitivo en estas pacientes antes de seis meses de control post-partum.

\section{TECNICA}

Hemos usado en la mayoría de los casos la técnica descrita por Kark y Muehrcke para biopsia percutánea en posición de decúbito abdominal. En dos casos hicimos la biopsia directamente durante operación cesárea. La descripción de la técnica, de una manera breve, es la siguiente: 
Exámenes de laboratorio.-Tiempo de coagulación y de sangría, protrombina, cuadro hemático y clasificación de grupo sanguíneo y factor $\mathrm{Rh}$.

Con la paciente en ayunas, se le administran 0.20 gramos de un barbitúrico (seconal) media hora antes. En pacientes aprehen. sivas y si su estado lo permite hemos usaǘo demerol 50 a 75 mili. gramos o clorpromazina 0.50 miligramos, vejiga urinaria vacía. Se coloca la paciente en posición de decúbito abdominal en la mesa quirúrgica. Un saco de arena de forma alargada de 45 centíme. tros de largo por 15 de diámetro, se coloca a través y por debajo del abdomen. Preparación del área quirúrgica, desde la región dorsal, hasta la parte superior de la región glútea. Con solución acuosa de violeta de genciana al $1 \%$ se traza una línea sobre las apófisis espinosas vertebrales de las regiones dorsal y lumbar, otra línea sobre la $12^{\text {a }}$ (duodécima) costilla derecha, otra sobre la cresta ilíaca derecha, otra sobre el borde externo del músculo cuadrado lumbar. Por último otra línea paralela a las apófisis espinosas y a una distancia aproximada de 8 centímetros de ellas. En esta forma tenemos un cuadrilátero que nos va a señalar el sitio de la biopsia, la que se hace generalmente a $1 \frac{1}{2}$ centímetros por deba. jo de la $12^{\text {a }}$ costilla o a $2 \frac{1}{2}$ centímetros por debajo de la $111^{a}$ costilla, si la anterior está ausente. Se inyecta procaína o xilocaína localmente en esta área. Se introduce una aguja exploradora número 20 de 7 pulgadas de longitud, ligeramente oblicua hacia el riñón. Se puede sentir la aguja atravesando los músculos, la fas_ cia lumbar profunda, la grasa perinefritica y la cápsula renal. Al respirar profundamente la enferma, la aguja describe un arco, oscilando el extremo opuesto a la punta, ampliamente si la aguja está en el riñón. Cuando no está, el arco es incompleto o no existe. Siguiendo a los trabajos de Dieckmann y colaboradores, nosotros no hemos hecho pielografías endovenosas para localizar el borde externo del riñón, según la técnica clásica; únicamente nos hemos basado en la posición anatómica del riñón y los movimientos efectuados con la respiración. Si hemos localizado el riñón medimos la profundidad del mismo en el tallo de la aguja e infiltramos con procaína el área a medida que retiramos ésta. Se hace una pequeña incisión para permitir la introducción fácil de la aguja de Vim-Silverman modificada, la cual se lleva en la misma dirección y a la misma distancia apreciadas anteriormente. Cuando se observa el balanceo característico, hacia la cabeza en la inspiración y hacia los pies durante la expiración, se introdu. cen las hojillas cortantes en toda su longitud en el tejido renal, 
y se avanza la aguja propiamente dicha sobre las mismas para hacerlas cortar el tejido renal. Estas maniobras aseguran un fragmento de tejido renal de 10 a 15 milímetro de longitud sin necesidad de hacer torción de la aguja. Se retiran las hojillas cortantes y la aguja. El tejido se introduce inmediatamente en una so lución de formol al $10 \%$. Se considera satisfactoria una biopsia que proporciona 5 o más glomérulos. Si hay necesidad se coloca un punto con seda en la pequeña incisión. Se aplica un vendaje compresivo y se hace permanecer a la enferma durante $1 / 2$ hora en la misma posición de decúbito abdominal y sobre la bolsa de arena. Es importante anotar que durante estas maniobras se le debe ordenar a la paciente suspender la respiración y permanecer quieta siempre que se introduzcan o retiren las hojillas cortantes y la aguja. El operador no debe manipular éstas cuando se balancean durante las maniobras de inspiración profunda. Si estas precauciones no se tienen en cuenta, el tejido renal se puede desgarrar. Se retira la aguja en un solo tiempo. Se mantiene la pa_ ciente en reposo durante 24 horas, controlándose durante este tiempo la tensión arterial, pulso y respiración y se anotan todas las sensaciones subjetivas en la historia.

Siempre se le pregunta a la paciente si hay dolor en la espal_ da, distensión en la vejiga urinaria, y urgencia para orinar. To_ das las muestras de orina se examinan macroscópica y microscópicamente durante 24 horas.

\section{TIPO DE PAIIENTES}

Las biopsias las hemos efectuado en pacientes con diagnósticos de pre_eclampsia leve, grave y eclampsia y en un caso consi. derado como eclampsia post-partum. Todos ellos han sido hechos por la vía percutánea, con excepción de dos casos, los cuales fueron hechos durante la operación cesárea. Hemos practicado 10 biopsias, así: 6 en pacientes multigestantes y 4 en pacientes primigestantes. De este total de biopsias hemos obtenido 6 resultados positivos para tejido renal, y el resto 4 , han sido negativas, habiéndose obtenido tejido conectivo o músculo estriado en estos últimos. La punción biopsia se practicó en $\&$ de ellos en el riñón derecho y no en el izquierdo para evitar la posibilidad de herir el bazo. Los dos restantes fueron obtenidos durante la operación ce. sárea que se le practicó a estas enfermas por causas diversas; obteniéndose la biopsia del riñón izquierdo para poder sostener la aguja y tomar la biopsia con ia mano derecha. 
Prácticamente no hemos tenido complicaciones post-biopsia Unicamnte en un caso observamos hematuria macroscópica (M57_2481) durante 12 horas aproximadamente, sin comprobar nin. guna complicación posterior. Es de anotar que en todas las pacientes sometidas a la biopsia renal se observa hematuria microscópica. En dos pacientes hubo queja de dolor en la región lumbar. Como en todo procedimiento quirúrgico se pueden presentar com. plicaciones en la biopsia, pero creemos que si se observa la técnica en todos sus detalles, se pueden reducir éstas a un mínimo. Es aconsejable practicar esta técnica en cadáveres para familiarizarse con el manejo de la aguja de Vim_Silverman, localización de los puntos de reparo, profundidad, dirección en que se debe introducir la aguja, etc. Siempre tenemos listos 1.000 c. c. de san. gre cuando vamos a practicar la biopsia renal.

\section{HALLAZGOS PATOLOGICOS}

Los cambios más significativos y constantes en las biopsias renales han sido los siguientes:

Cambios en el glomérulo: 1) isquemia. 2) Engrosamiento de la membrana basal. 3) Vacuolización del citoplasma. 4) Engrosa. miento ligero de los vasos aferentes. 5) Material de aspecto fibrinoide eosinófilo dentro de la cápsula de Bowman. 
PATOLOGIA DE LAS BIOPSIAS RENALES

\begin{tabular}{|c|c|c|c|c|c|c|}
\hline Número & Edad & $\begin{array}{l}\text { Diagnóstico clínico } \\
\text { provisionaI }\end{array}$ & $\begin{array}{l}\text { Edad del } \\
\text { Emba- } \\
\text { razo }\end{array}$ & $\begin{array}{l}\text { Gravi- } \\
\text { dez }\end{array}$ & $\begin{array}{l}\text { Tensión Ar- } \\
\text { teŕal Edema- } \\
\text { Proteinuria }\end{array}$ & H A L L A Z G O S \\
\hline M_57_3113 & 35 & Pre_eclampsia leve & 40 & 10 & $\begin{array}{l}150 / 90 \\
+t \\
++\end{array}$ & Glomérulos sin ninguna lesión aparente. \\
\hline M__57_3210 & 37 & $\begin{array}{l}\text { Hipertensión crónica con } \\
\text { toxemia sobre_agregada. }\end{array}$ & 32 & 13 & $\begin{array}{l}260 / 140 \\
+ \\
++++\end{array}$ & $\begin{array}{l}\text { Solo se observa tejido medular ligero infil_ } \\
\text { trado mononuclear hacia la pelvis. }\end{array}$ \\
\hline M_57_1477 & 38 & Eclampsia. & 36 & 1 & $\begin{array}{l}180 / 100 \\
++ \\
++++\end{array}$ & $\begin{array}{l}\text { Engrosamiento de la basal de las asas glome- } \\
\text { rulares. Material fibrinoide eosinófilo dentro de } \\
\text { la cápsula de Bowman. Ligero engrosamiento } \\
\text { de la pared en las arteriolas aferentes. }\end{array}$ \\
\hline M_57_3184 & 20 & Pre_eclampsia. & 33 & 2 & $\begin{array}{l}150 / 90 \\
++ \\
+++ \\
\end{array}$ & $\begin{array}{l}\text { No hay alteración histológica en los gloméru. } \\
\text { los. Capilares glomerulares exanguies, cilindros } \\
\text { hialinos dentro de los tubos. }\end{array}$ \\
\hline M_57_3133 & 32 & Pre_eclampsia severa. & 40 & 1 & $\begin{array}{l}170 / 110 \\
++ \\
++t\end{array}$ & $\begin{array}{l}\text { Aumento del tamaño de los glomérulos, sus_ } \\
\text { tancia homogénea eosinófila entre las asas glo_ } \\
\text { merulares. }\end{array}$ \\
\hline M_57_2481 & 21 & Pre_eclampsia leve. & 42 & 1 & $\begin{array}{l}150 / 90 \\
++ \\
+++\end{array}$ & $\begin{array}{l}\text { Células epiteliales coloreadas pertenecientes } \\
\text { a glomérulos. Capa basal engrosada. }\end{array}$ \\
\hline M_57_2060 & 22 & Eclampsia. & 38 & 1 & $\begin{array}{l}170 / 120 \\
++ \\
++++\end{array}$ & $\begin{array}{l}\text { Tejido conectivo y adiposo sin alteraciones } \\
\text { patológicas. }\end{array}$ \\
\hline M_57_3062 & 36 & Eclampsia puerperal & - & 6 & $\begin{array}{l}150 / 105 \\
++++ \\
++++\end{array}$ & $\begin{array}{l}\text { Material insuficiente. Tejido muscular es_ } \\
\text { triado. }\end{array}$ \\
\hline M_57_1473 & 18 & Eclampsia. & 40 & 1 & $\begin{array}{l}150 / 110 \\
+ \\
++++\end{array}$ & Músculo estriado. \\
\hline M_57_1444 & 17 & Eclampsia. & 40 & 1 & $\begin{array}{l}210 / 95 \\
++ \\
+++\end{array}$ & Material insuficiente. \\
\hline
\end{tabular}

